Volume 14 - Número 2 - ago/dez de 2019

\title{
ANÁLISE CRÍTICA DO DISCURSO MULTIMODAL DE REPRESENTAÇÕES DA MULHER NA MÚSICA POP: UM ESTUDO DE CASO SOBRE A IMAGEM DINÂMICA
}

\author{
MULTIMODAL CRITICAL DISCOURSE ANALYSIS OF REPRESENTATIONS OF \\ WOMEN IN POP MUSIC: A CASE STUDY ABOUT THE DYNAMIC IMAGE
}

\author{
Fábio Alexandre Silva Bezerra ${ }^{1}$ \\ Brenda Aureliano Gomes ${ }^{2}$
}

\begin{abstract}
RESUMO: Este artigo, tendo como objeto de análise o videoclipe da música Mrs. Potato Head, da cantora Melanie Martinez, objetiva discutir as representações da mulher construídas por meio do texto multimodal tendo em vista suas marcas ideológicas e as relações de poder nele imbricadas. Para tal, fazemos uso de estudos em Multimodalidade e Análise Crítica do Discurso, a partir de conceitos e categorias de análise da gramática do design visual de Kress e van Leeuwen (2006), bem como do modelo tridimensional de Fairclough (2015[1989], 1995). Os resultados demostram que as representações da mulher são marcadas pelas ações e discursos de dois agentes principais: a figura masculina e a mídia, a partir da influência de visões hegemônicas sobre beleza e das relações assimétricas de poder entre homem e mulher.
\end{abstract}

PALAVRAS-CHAVE: Multimodalidade. Análise crítica do discurso. Mídia. Representações da mulher.

ABSTRACT: This paper, whose object of analysis is the music video Mrs. Potato Head, by Melanie Martinez, aims to discuss the representation of women constructed through the multimodal text in view of their ideological marks and its implicated power relations. For that, studies in Multimodality and Critical Discourse Analysis are used, based on concepts and categories of grammar of visual design by Kress and van Leeuwen (2006), as well as the tridimensional model by Fairclough (1995). Results show that the representations of the women in the multimodal text are marked by the actions and discourse of two main agents: the male figure and the media, based on the influence of the hegemonic views of beauty and the asymmetrical power relations between men and women.

KEYWORDS: Multimodality. Critical discourse analysis. Media. Representations of women.

\section{Introdução}

Com a disseminação dos recursos tecnológicos, que dão suporte a uma grande variedade de gêneros textuais na sociedade contemporânea, torna-se evidente a importância de conhecer suas potencialidades com vistas a uma melhor compreensão sobre seus usos nas diversas esferas da experiência humana. Nesse contexto, é preponderante o papel da mídia na produção e disseminação de sentidos acerca dos mais variados temas e esferas de atuação em sociedade.

Esse uso mais disseminado dos recursos tecnológicos tem, cada vez mais, criado uma sociedade com um modo de tratar o conhecimento e a reflexão crítica de maneira distinta, moldados por informações recebidas em grande escala e em velocidade sem precedentes, visto que "imagens, sons e espetáculos ajudam a produzir o tecido da vida cotidiana, dominando o tempo de lazer, moldando visões políticas e o comportamento social, e fornecendo os materiais com os quais as pessoas forjam suas próprias identidades" (KELLNER, 2003, p. 1). ${ }^{3}$

Evidencia-se, dessa maneira, a importância de se desenvolver práticas, especialmente no contexto escolar, que visem ao desenvolvimento de leitura crítica dos mais variados gêneros textuais em diversos suportes midiáticos, precisamente por exercerem impacto direto na

\footnotetext{
1 Doutor em Língua Inglesa e Linguística Aplicada pela Universidade Federal de Santa Catarina. PhD em Linguística pela University of Sydney. Docente do Departamento de Letras Estrangeiras Modernas e do Programa de Pós-Graduação em Linguística da Universidade Federal da Paraíba. E-mail: fabes10@yahoo.com.br.

${ }^{2}$ Graduada em Letras - Inglês pela Universidade Federal da Paraíba. E-mail: brendag_@live.com.

${ }^{3}$ Todas as traduções feitas neste artigo são de responsabilidade dos autores.
} 
Volume 14 - Número 2 - ago/dez de 2019

maneira como entendemos nossa cultura e nossas histórias individuais e coletivas (KELLNER; SHARE, 2008).

Para o desenvolvimento da leitura crítica da mídia, a utilização de princípios e conceitos da Análise Crítica do Discurso (ACD) se apresenta como uma alternativa eficiente, visto que é dada atenção tanto para parâmetros textuais como contextuais por meio da análise das práticas discursivas e das práticas sociais, revelando aspectos importantes das representações e das relações construídas por meio do texto em análise (MEURER, 2005).

O poder constitutivo do discurso pode se manifestar a partir da percepção da criação de distintas representações de realidade, moldando-se o senso comum por meio da consolidação e disseminação de ideologias particulares. Alguns grupos sociais sofrem mais as consequências desse domínio que outros, em geral grupos minoritários e/ou que historicamente foram/são mantidos em posições de inferioridade material e/ou simbólica.

Compreendemos que a língua/linguagem tem um potencial tanto de questionamento quanto de manutenção das relações sociais, que, muitas vezes, contribui para a sobrevivência de estereótipos sobre os mais diversos aspectos da vida em sociedade (LAKOFF, 2003). A esse respeito, Heberle (2000, p. 5) assevera que "certas representações mentais são compartilhadas por membros de uma determinada comunidade discursiva, e podem ser incorporadas na sociedade, tornando-se, assim, parte da cognição social”, contribuindo, dessa maneira, para a manutenção de certas visões e atitudes quanto a determinados grupos sociais.

Para a discussão dessa temática no presente artigo, apresentamos uma análise crítica do discurso multimodal de um videoclipe, objetivando, também, compreender como a imagem dinâmica constrói sentidos em uma perspectiva multimodal. $\mathrm{O}$ videoclipe escolhido é intitulado Mrs. Potato Head, da cantora estadunidense Melanie Martinez. Por meio do suporte teóricometodológico da ACD e da gramática do design visual de Kress e van Leeuwen (2006), com foco em sua metafunção representacional, esse texto multimodal é analisado com vistas à discussão das distintas maneiras de representações da mulher e do impacto da mídia e da figura masculina nesse contexto. Ademais, as análises multimodais e críticas do discurso são complementadas a partir de discussões relativas ao gênero e à leitura crítica da mídia.

O objetivo geral da pesquisa é, portanto, investigar a representação das identidades da mulher no conjunto videoclipe/letra em questão, tendo em mente suas marcas ideológicas e as relações de poder representadas no texto. Para tal, este estudo se orienta pelos seguintes objetivos específicos:

a) Identificar ideologias e relações de poder na letra da música Mrs. Potato Head e no seu videoclipe a fim de verificar como a mulher é representada;

b) Desenvolver uma análise multimodal do videoclipe e detectar os recursos utilizados para que tais representações sejam feitas; e

c) Descrever como a mídia e o discurso hegemônico podem influenciar a percepção social sobre relações de gênero.

\section{Fundamentação teórica}

Neste artigo, são utilizados conceitos da Análise Crítica do Discurso (FAIRCLOUGH, 2015[1989], 1995; MEURER, 2005; WODAK, 2004) para sustentar discussões acerca da leitura crítica da mídia (CORACINI; CARMAGNANI, 2014; KELLNER; SHARE, 2008), bem como conceitos e categorias de análise da gramática do design visual (KRESS; VAN LEEUWEN, 2006) a fim de fundamentar descrições do texto multimodal. Por fim, são feitas algumas considerações acerca de identidades de gênero e do discurso (HEBERLE, 2000). 
Volume 14 - Número 2 - ago/dez de 2019

\subsection{Análise crítica do discurso da mídia}

Na sociedade contemporânea, é premente a atenção para questões de relevância social com vistas ao desenvolvimento de processos sociais mais inclusivos, que atentem para a maneira como desigualdades são constituídas e mantidas a fim de propor caminhos para seu questionamento e superação. Um elemento essencial nesse contexto é o papel da linguagem em uso, i.e. do discurso, na manutenção e/ou no desafio dessas inequidades (WODAK, 2004). A fim de tratar desse aspecto constitutivo do discurso, Fairclough (2015 [1989], 1995) propõe uma análise tridimensional do evento discursivo: como texto, como prática discursiva e como prática social.

Todo texto é compreendido como refletindo certas práticas discursivas e inserido em determinadas práticas sociais. A análise do evento discursivo como texto considera o ato de descrever esse texto a partir de suas marcas mais concretas, mais próximas dos "significados literais do texto" (MEURER, 2005, p. 94), destacando as opções gramaticais, lexicais e de coesão presentes no texto e de suas implicações ideológicas. Nessa dimensão, interessa-nos compreender, por exemplo, por que certas palavras foram escolhidas em determinados contextos.

Na dimensão das práticas discursivas, o trabalho do analista é de interpretação, pois aborda o evento discursivo a partir de questões que envolvem aspectos de sua produção, distribuição e consumo, i.e. "quem escreve para quem, em quais circunstâncias, por quê?" (MEURER, 2005, p. 101). Esses novos dados acrescentam informações contextuais aos dados textuais destacados na dimensão de análise anterior com vistas a uma compreensão mais ampla sobre a constituição do texto como evento discursivo.

Por fim, analisando o evento discursivo como prática social, são observadas questões ainda mais amplas, que impactam o evento discursivo em questão e que também podem ser impactadas pelo mesmo, em uma relação de bidirecionalidade. Dentre essas questões, podemos destacar aspectos ideológicos presentes no texto, marcas de constituição de identidades particulares, representações de grupos sociais a partir de seus marcadores sociais, tais como: classe social, gênero, sexualidade, idade e escolaridade. Em outras palavras, buscamos associar a análise do texto e de suas práticas discursivas com aspectos globais, sociais e institucionais que atravessam o texto como evento discursivo a fim de discutirmos de que maneira ele contribui para a manutenção ou superação de certas relações sociais, valores e práticas.

\subsection{Multimodalidade: a gramática do design visual}

O presente estudo também se pauta por estudos em multimodalidade e multiletramentos (COPE; KALANTZIS, 2000). Há diversos modos pelos quais a comunicação pode se dar na atualidade - imagens, vídeos, músicas, etc. -, e mesmo "em textos predominantemente verbais, utilizamos recursos visuais, tais como tipografia e formatação" (NASCIMENTO; BEZERRA; HEBERLE, 2011, p. 530).

Sendo assim, é notória a importância de uma abordagem multimodal e do desenvolvimento de práticas de multiletramentos (COPE; KALANTZIS, 2015) na contemporaneidade a fim de que possamos desenvolver competências imprescindíveis para a vida em sociedade ao compreendermos que sentidos são construídos por meio da inter-relação de modos semióticos diversos em arquiteturas multimodais específicas.

Kress e van Leeuwen (2006) propõem conceitos e categorias de análise em sua gramática do design visual para a análise e interpretação do texto multimodal a partir de três dimensões, ou metafunções: representacional, interacional e composicional. Como a ênfase das análises e da discussão apresentadas neste artigo são nas representações da mulher em Mrs. Potato Head, apresentamos, a seguir, os principais conceitos e categorias de análise descritos 
apenas na dimensão de representação, que trata de como as imagens constroem representações de realidade, sendo subdividida em representações narrativas e representações conceituais.

A representação narrativa diz respeito a "ações, reações, pensamentos e fala" (BEZERRA, 2012, p. 170). Os processos de ação e reação requerem vetores para que sejam identificados, podendo ser subdivididos em transacionais e não-transacionais.

Figura 1: Processo de ação transacional bidirecional

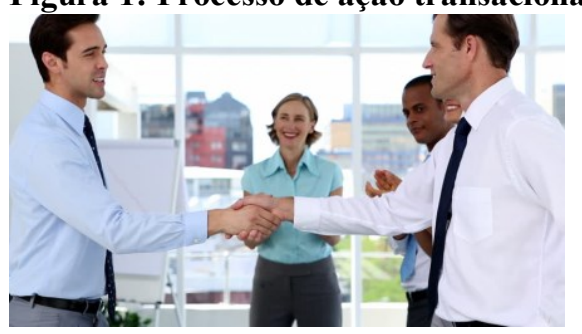

Fonte: https://ak3.picdn.net/shutterstock/videos/
Figura 2: Processo de reação não-transacional

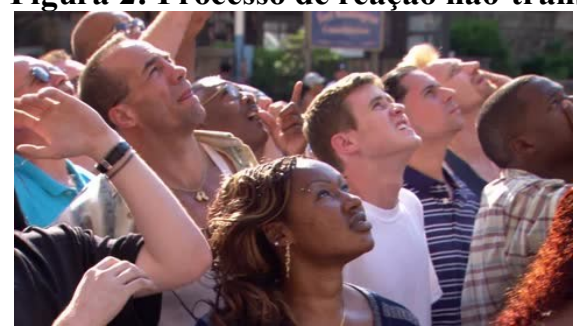

Fonte: https://ak3.picdn.net/shutterstock

Na Figura 1, vemos um processo de ação (aperto de mãos), que pode ser notado pelo vetor formado pelos braços dos dois participantes. O processo é transacional, pois os participantes dinâmico (ator) e passivo (meta) ${ }^{4}$ podem ser vistos na imagem, sendo, ainda, bidirecional, já que a ação é performada por ambos ao mesmo tempo, ocupando, no mesmo evento discursivo, as posições dinâmica e passiva. Na Figura 2, temos participantes diferentes envolvidos em processos de reação individuais, identificados pela linha do olhar. Essa reação é não-transacional, visto que não podemos ver, na imagem, o fenômeno para o qual os participantes (reatores) estão olhando.

Nas representações narrativas, conforme ilustrado na Figura 3, também podem ocorrer outros dois tipos de processos: verbal (representado por balões de fala) e mental (caracterizado pela presença na imagem de balão de pensamento).

Figura 3: Processos verbal e mental

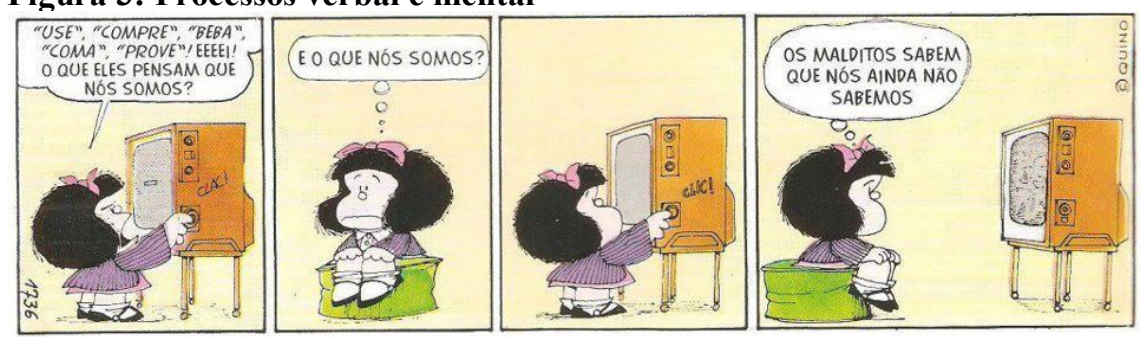

Fonte: http://www.cweden.com/snoopy/comicstrips/eng020604.gif

Além das representações narrativas, também há a possibilidade de o texto multimodal construir representações conceituais. Esses conceitos podem ser identificados por meio da mobilização de três diferentes estratégias: foco nas identidades (processo de classificação), nos atributos dos participantes (processo analítico) e nas características distintivas de certos elementos da imagem (processo simbólico). A Figura 4 ilustra um processo classificatório implícito, pois não há elemento explicitando que os objetos são cervejas, mas é possível concluir a classificação sendo feito pela similaridade que os elementos da imagem possuem entre si.

\footnotetext{
${ }^{4}$ Participantes dinâmicos e passivos são aqueles que fazem agem/reagem e aqueles que recebem a ação/reação, respectivamente.
} 
Volume 14 - Número 2 - ago/dez de 2019

Figura 4: Processo de classificação

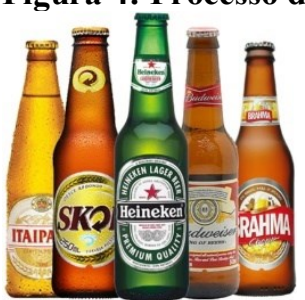

Fonte: https://mambo.vteximg

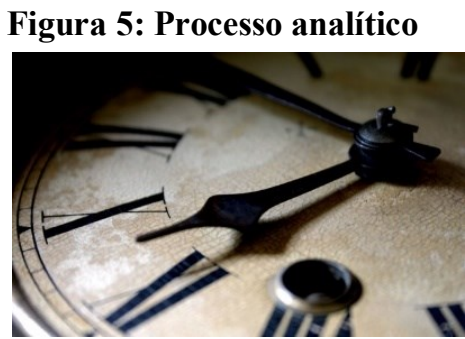

Fonte: https://mambo.vteximg
Figura 6: Processo simbólico

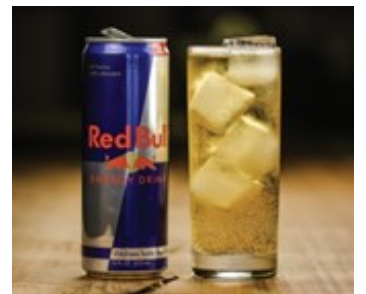

Fonte: https://mambo.vteximg

Ademais, há também os processos analíticos, que compõem uma relação de parte/todo na imagem, ou seja, a presença de um elemento que simbolize um componente completamente, mesmo que seja mostrada só sua parte. Na Figura 5, por exemplo, é possível notar o foco apenas nos ponteiros do relógio, mas interpreta-se que a intenção da imagem é de representar a passagem do tempo ao identificarmos que se trata de um relógio.

Por fim, a Figura 6 mostra um processo simbólico, que consiste na "presença de elementos na imagem que acrescentam valor extra, justamente por não serem intrínsecos a ela" (NASCIMENTO; BEZERRA; HEBERLE, 2011, p. 538). Nessa imagem, é possível notar que os touros presentes no logotipo da marca de energéticos Redbull conferem uma ideia extra sobre a substância, dando a entender que a bebida realmente dará energia a quem bebê-la, assim configurando um processo simbólico analítico.

É importante ressaltar que, para os nossos fins específicos, a análise será baseada na imagem dinâmica, uma vez que se trata de um videoclipe, e não de fotos isoladas. Sobre isso, van Leeuwen (1996, p. 81) afirma que,

Em imagens estáticas, ações e transações são realizadas através de vetores. Imagens móveis também podem realizar ações e transações, entretanto elas não o fazem por meio de vetores, e sim através do movimento. Não é o vetor formado por uma mão estendida segurando a arma que realiza a ação de "mirar", mas sim o próprio movimento do braço ao levantar a arma e apontá-la. Em outras palavras, nas imagens em movimento as ações são realizadas por meio de ações, e as transações por meio de transações.

Dito isso, podemos concluir que é possível perceber que os dois tipos de imagens (estática e dinâmica) possuem suas particularidades, mas funcionam de modos semelhantes, de acordo com as suas nuances, que devem ser observadas e destacadas na análise.

\subsection{Identidades e discurso}

Considerando a necessidade de leitura crítica da mídia e as particulares do texto multimodal e da análise do discurso que o constitui, também é essencial que explicitemos a interferência que o meio social pode ter sobre essa construção e, por conseguinte, a importância de compreendê-la a fim de possibilitar a análise dos dados desta pesquisa. No contexto da presente pesquisa, uma das categorias sociais mais relevantes é o gênero, visto que analisamos e propomos discussão de representações da mulher no texto multimodal em questão.

É importante, portanto, que entendemos gênero como um construto social, que ultrapassa a simples dicotomia biológico entre masculino e feminino. Nesse sentido, o gênero "atravessa outras variáveis sociais, tais como (...) idade, grau de escolaridade, etnia, status socioeconômico, ocupação, classe social, orientação sexual, filiação política/religiosa" (HEBERLE, 2000, p. 13), revelando, assim, a complexidade da questão de gênero, que demanda atenção do analista para os parâmetros contextuais específicos de cada situação no intuito de evitar generalizações sobre experiências que são, na verdade, individuais. 
Além disso, de acordo com Benwell e Stokoe (2006), “diferentes descrições podem ser produzidas, nas quais algumas 'identidades' são enfatizadas e outras são ignoradas ou menosprezadas." (p. 3), criando, dessa maneira, mais um alerta para o analista no sentido de observar com atenção os espaços que são criados para que certas representações sobre as identidades da mulher e do homem tome destaque no texto em análise.

Portanto, as análises desenvolvidas neste artigo procuram articular a noção de gênero como construto social, evitando generalizações que apaguem especificidades contextuais, ao mesmo tempo em que buscam articular os sentidos construídos sobre gênero por meio da linguagem verbal e da linguagem imagética em materializações discursivas marcadas por questões sociais complexas.

\section{Metodologia}

Inicialmente, partimos da ideia de utilizar o CD Cry Baby, da cantora Melanie Martinez, integralmente, fazendo uso da característica narrativa que ele carrega, ao utilizar as faixas do disco e sua ordem de aparição para contar uma única história. Ao afunilar esse foco, veio à tona a relevância dos temas transversais presentes nessa história, como questões de orientação sexual (a descoberta sexual de Cry Baby) e saúde (alcoolismo), por exemplo. A partir disso, foram selecionados os temas-chave adequados, que incluíam principalmente os temas Ética, Saúde e Orientação Sexual. Em seguida, foi selecionada a música do álbum que parecia tratar da temática de maneira mais ampla, Mrs. Potato Head, qual seja a influência da mídia e da figura masculina sobre a figura da mulher.

Como o foco da pesquisa está em investigar as representações da mulher no videoclipe em questão, o texto imagético foi analisado com base na metafunção representacional descrita na gramática do design visual de Kress e van Leeuwen (2006) e a letra da música foi analisada a partir da observação de quais participantes estão envolvidos na narrativa, as ações nas quais estão envolvidos e as qualificações/descrições que são feitas sobre coisas, pessoas e lugares.

Em seguida, é feita a análise crítica do discurso do texto multimodal com vistas à interpretação das práticas discursivas nas quais o texto se insere e à explicação das práticas sociais mobilizadas pelo texto a partir do modelo tridimensional de Fairclough (2015[1989], 1995).

Após selecionar cada um desses elementos na letra, dividimos a música em partes a fim de determinar onde elas se encaixariam na análise do vídeo. Foi perceptível que algumas estrofes correspondiam de modo mais direto a algumas partes do vídeo, então essa foi a forma escolhida para a organização do texto. Ainda assim, é importante notar que a letra, em um contexto geral, possui ligação com o vídeo inteiro. Vale, ainda, ressaltar que, para fins deste artigo, apenas alguns frames $^{5}$ de cada sequência do videoclipe são apresentados, devido a questões de espaço disponíveis para esta publicação. No entanto, informamos que as análises foram feitas com um considerável nível de detalhamento acerca da imagem dinâmica, com quadros capturados com base no intervalo de apenas um (1) segundo.

$\mathrm{Na}$ seguinte seção, é explicitada a fundamentação teórica desta pesquisa. Em seguida, apresentamos as análises e discussões acerca do objeto de estudo. Por fim, fazemos algumas considerações finais, onde é feito um apanhado dos resultados finais da pesquisa.

\footnotetext{
${ }^{5} \mathrm{O}$ termo frame (em português, quadro) será utilizado neste artigo para evitar confusão com os quadros utilizados ao longo do texto para apresentação das partes da letra da música.
} 
Volume 14 - Número 2 - ago/dez de 2019

\section{Análise e resultados}

Tendo em vista a extensão do videoclipe e o grande número de quadros que são utilizados para análise, foi feita uma divisão em seis sequências de modo a facilitar o entendimento e a própria análise. Cada sequência representa momentos específicos do vídeo, que são estabelecidos a partir de elementos espaciais e temporais, tendo sido essa a lógica escolhida para a separação em sequências.

Neste capítulo, apresentamos a análise multimodal e crítica do discurso do videoclipe e da letra da música em análise, desenvolvendo reflexões sobre questões de gênero e a influência da mídia na contemporaneidade.

Tabela 1: Sequência 1 do videoclipe da música Mrs. Potato Head.

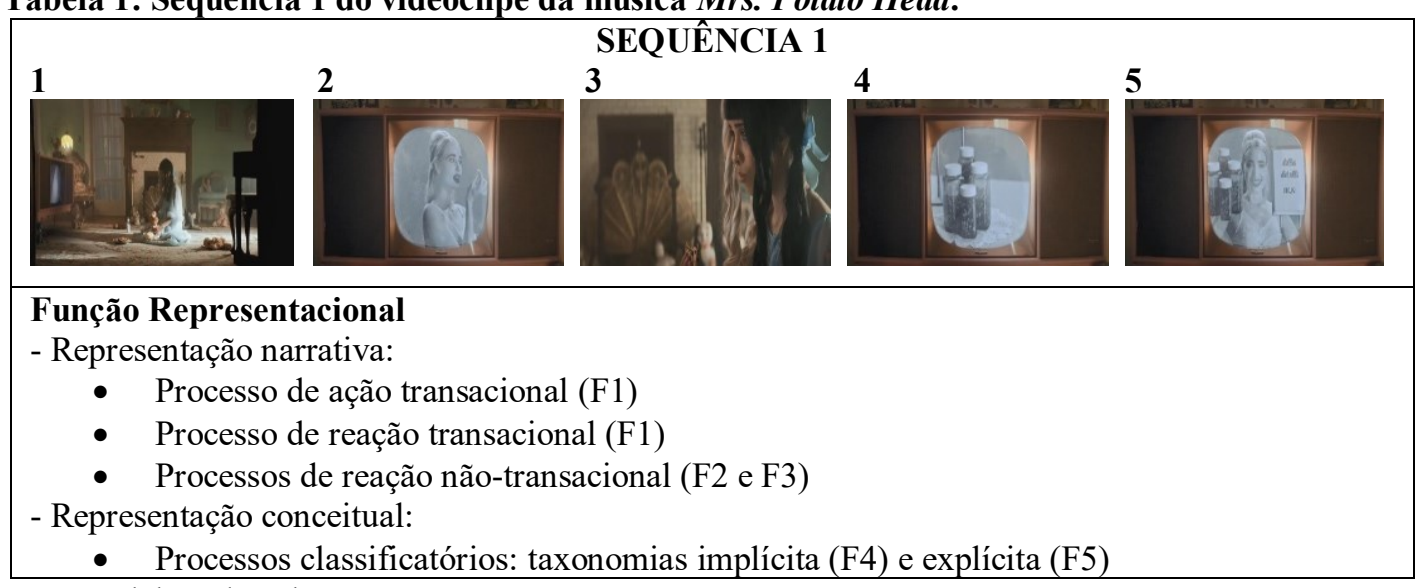

Fonte: Elaborada pelos autores.

A sequência 1 (Tabela 1) trata da personagem, chamada Cry Baby, assistindo a um comercial de televisão enquanto come biscoitos. Sentada à frente da TV, Cry Baby vê a mulher no comercial oferecer diversos produtos de beleza. Com base na metafunção representacional, é possível notar, dentro da representação narrativa, processos de ação e de reação transacionais no $\mathrm{F}^{6}{ }^{6}$, dando foco à personagem comendo o biscoito, brincando com a boneca e assistindo ao comercial de TV. Além desses, há também o processo de reação mostrado no F3, traduzindo a influência do bombardeio de informações gerado pela propaganda sobre a personagem, cuja única reação é parar de comer e observar. A representação conceitual também se faz presente nessa sequência: nos F4 (implícita) e F5 (explícita), é possível observar processos classificatórios reforçando a venda das pílulas de emagrecimento.

A fim de relacionar o vídeo com a letra da música, analisamos a presença de ações, de participantes envolvidos nas mesmas, bem como de características que são atribuídas a esses participantes na medida em que possam revelar questões relevantes para questões identitárias. A partir de conceitos da ACD, são trazidas conexões entre os elementos linguísticos na imagem e no texto verbal, e ainda a análise do texto em questão com base nas práticas discursivas e sociais em que está inserido.

Quadro 1: Primeira estrofe da música Mrs. Potato Head

\begin{tabular}{l}
\hline If you weren't born with it \\
You can buy a couple ornaments \\
Just be sure to read the warning kids \\
'Cause pretty soon you'll be bored of it \\
(Ha, ha) \\
Fonte: Elaborado pelos autores.
\end{tabular}

\footnotetext{
${ }^{6} \mathrm{~F} 1=$ Frame $1, \mathrm{~F} 2=$ Frame 2, e assim por diante.
} 
Volume 14 - Número 2 - ago/dez de 2019

Na primeira estrofe (Quadro 1), a letra propõe a adição de novos ornamentos a fim de melhorar sua aparência caso se sinta necessário. A presença do pronome pessoal you (você) nos dois primeiros versos indica que a mensagem é voltada para todas as pessoas que não nasceram com tais atributos (na sentença "if you weren't born with it"), adicionando, assim, um participante a essa circunstância. Em seguida, vemos que, ao utilizar kids (crianças) diretamente, a cantora afunila o público-alvo das mensagens para pessoas mais jovens, dando força à metáfora traçada com o brinquedo de montar.

A presença dos processos to be born (nascer), relacionado ao sujeito you, e to buy (comprar) fazendo contato direto com ornaments (ornamentos) sugerem o fato de que você nascer sem os atributos físicos valorizados socialmente conduz à ação de comprar objetos que possam oferecer algum tipo de aperfeiçoamento de sua imagem. Esses ornamentos também podem ser entendidos como resultados alcançáveis por meio de uma cirurgia plástica, uma vez que esse é um dos principais temas do vídeo. As partes do videoclipe que mostram Cry Baby se maquiando e colocando a peruca (sequência 2), bem como a Mrs. Potato Head fazendo a cirurgia e sendo presenteada com, também, uma peruca (visto mais adiante, nas sequências 4, 5 e 6), ilustram a presença desses ornamentos na história.

Posteriormente, nos versos números três e quatro da estrofe, há mais três elementos principais: a ação to read (ler), o componente warning (aviso) e a ação to be bored (ficar entediado ou, mais adequado ao caso presente, cansar-se de algo). Esses três elementos, novamente voltados para o mesmo público-alvo anterior, insinuam que existe a possibilidade de haver desvantagens nesse processo, aqui representado como uma cirurgia plástica, então deve-se tomar bastante cuidado antes de decidir por esse procedimento. Isso também é mostrado mais adiante, através das ações do Mr. Potato Head (sequência 6), que se cansou da aparência da parceira mesmo após a cirurgia e os presentes, e resolveu trocá-la por outra pessoa.

$\mathrm{Na}$ Tabela 2, a sequência 2 dá continuação direta para o que foi visto até este ponto, revelando as influências que o comercial de TV mostrado no vídeo teve sobre a personagem, além de dar sentido às informações adquiridas a partir da primeira estrofe - Cry Baby não sente que possui os atributos necessários para se encaixar nos padrões sociais e decide buscar outros meios para atingi-lo.

Tabela 2: Sequência 2 do videoclipe da música Mrs. Potato Head.

SEQUENCIA 2
Função Representacional
- Representações narrativas:
• Processos de ação transacional (F8 a F11)
- Processo de reação transacional (F7)
- Representações conceituais:
• Processos simbólico: peruca loira (F7 a F11)

Fonte: Elaborada pelos autores.

Nessa sequência, o ponto de partida são observações referentes à função representacional. É possível observar diversos processos de ação e de reação durante a sequência. Os processos de ação (passar batom, colocar peruca e tomar pílulas), vistos nos F8 a F11, mostram as atitudes da personagem em relação ao que foi visto anteriormente: ela foi diretamente afetada pelas imagens do comercial, resolvendo agir por conta própria em busca da beleza oferecida. Enquanto isso, o processo de reação (F7) possui foco no semblante da personagem, indicando a tristeza e o conflito que ela está sentindo no momento. 
Volume 14 - Número 2 - ago/dez de 2019

Dentro da função de representação, ainda é possível descrever as representações conceituais. Aqui, mais especificamente, podemos observar um processo simbólico: a peruca loira, que fará mais aparições posteriormente. Nesse momento, a peruca carrega um significado além da superfície, dando à mulher representada características que não a pertencem naturalmente, e, possivelmente, fazendo-a refém de padrões estéticos impostos pela sociedade.

Tabela 3: Sequência 3 (primeira parte) do videoclipe da música Mrs. Potato Head.

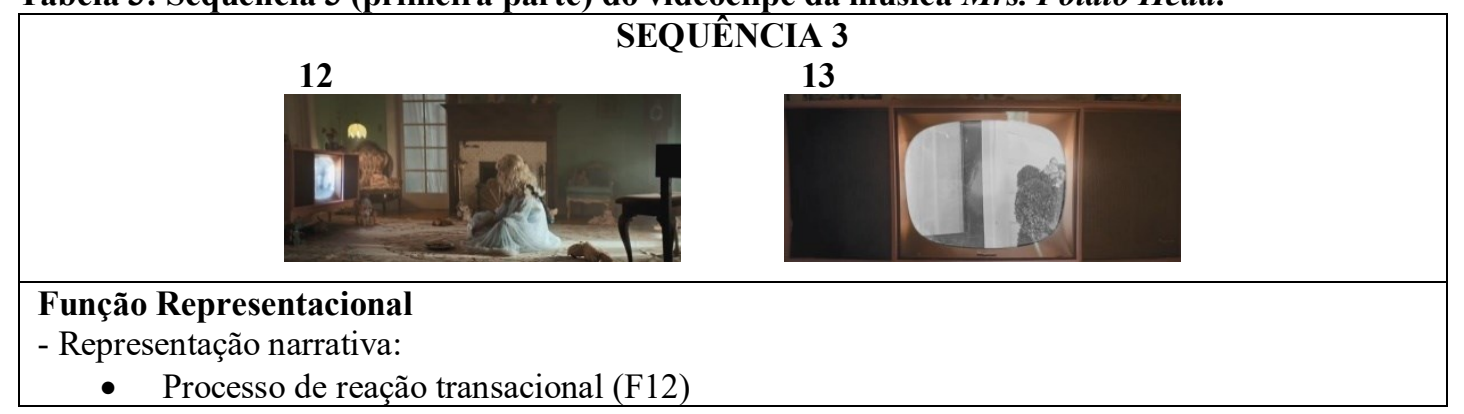

Fonte: Elaborada pelos autores.

A sequência 3 (Tabela 3 ) se inicia com uma cena similar à que dá início à sequência 1 . Apesar das semelhanças, o processo de reação transacional carrega uma mudança de sentido, conferida pela transformação da personagem a partir dos elementos comportamentais estimulados pelo comercial de pílulas para emagrecimento. Tal mudança pode ser observada por meio da presença do processo simbólico representado pela peruca loira e pelo fato de a participante não estar mais comendo.

Tabela 4: Sequência 4 do videoclipe da música Mrs. Potato Head.

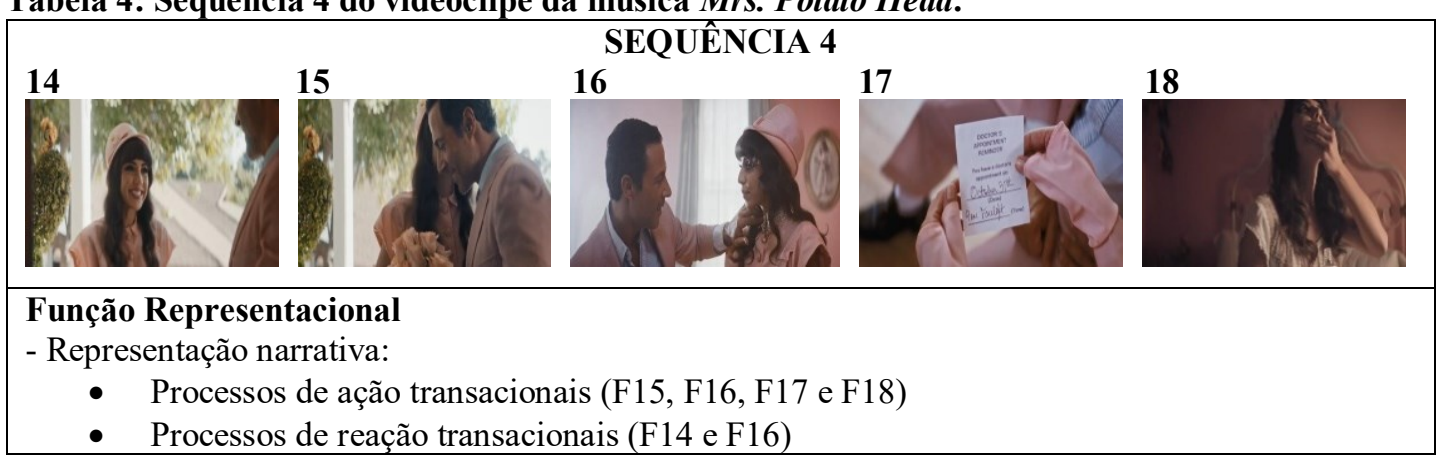

Fonte: Elaborada pelos autores.

Essa sequência (Tabela 4) mostra uma nova personagem, a Mrs. Potato Head. Seu nome é baseado em uma série de brinquedos formados por uma cabeça em forma de batata e cujas partes (olhos, boca, etc.) são removíveis, podendo ser trocadas indiscriminadamente. A partir dessa relação, a cantora e compositora Melanie Martinez traçou uma metáfora entre o brinquedo e cirurgias plásticas, problemática abordada nesta estória.

Levando em consideração as roupas que a Mrs. Potato Head veste durante toda a sequência, é possível presumir que os eventos narrados ocorrem em tempos remotos. Com isso, devemos observar toda a narrativa com outros olhos. A metafunção de representação narrativa, vista nos F15 a F18, mostra processos de ação e de reação, indicando proximidade entre os dois personagens, ilustrando um relacionamento aparentemente comum de um casal.

No F16, podemos observar o início da imposição de padrões de beleza pela figura masculina, visto que o homem, após presenteá-la com um colar, entrega-lhe um papel com o horário de uma consulta médica para procedimentos estéticos. É possível notar que o background foi desfocado para que houvesse foco no conteúdo do papel. A personagem, mesmo 
Volume 14 - Número 2 - ago/dez de 2019

pega de surpresa e parecendo não gostar tanto da ideia, acata o pedido e começa a se preparar para a cirurgia.

\begin{tabular}{|} 
Quadro 2: Segunda estrofe da música Mrs. Potato Head \\
Sexual \\
Hey girl, if you wanna feel sexual \\
You can always call up a professional \\
They stick pins in you like a vegetable \\
(Ha, ha)
\end{tabular}

Fonte: Elaborado pelos autores.

A partir do que foi representado nessa parte da música, podemos traçar outro paralelo, dessa vez com a segunda estrofe (Quadro 2). Há a presença do primeiro elemento de característica da música, "sexual”, em conexão com o participante girl (menina). Observamos que a escolha da palavra garota para se referir à figura feminina parece bem específica: a cantora poderia tê-la chamado de mulher, por exemplo, visto que a personagem do vídeo é uma adulta. Vemos, assim, novamente, um direcionamento a um público alvo mais jovem, de forma a educar garotas mais novas. Esse substantivo é seguido de dois elementos em conexão: o processo to feel (sentir) e, mais uma vez, a característica sexual, levando às próximas duas unidades, que são a ação to call up (ligar) e o participante professional (profissional). Isso mostra que há sempre uma solução para o desejo de se sentir mais sexual; para a narrativa vista no vídeo, esse desejo e essa solução foram impostos pela figura masculina, como demonstrado nos F16 e F17.

Por fim, to stick (furar), pins (alfinetes) e vegetable (vegetal) elaboram uma metáfora que parece denominar como banal todo o processo cirúrgico pelo qual a personagem irá passar; processo esse que, pelo senso comum, sabe-se ser algo bastante complicado. Ao dizer que o profissional irá "furar você como um vegetal", uma atividade que poderia ser vista no dia-a-dia de uma pessoa comum, há um espelho das atitudes do homem da história, que entrega o papel com a consulta médica como se isso não fosse importante ou precisasse do consentimento da Mrs. Potato Head. Essas atitudes, em somatória com a frase acima, atribuem característica trivial a toda a cirurgia.

Tabela 5: Sequência 5 do videoclipe da música Mrs. Potato Head.

SEQUENCIA 5
Função Representacional
- Representação narrativa
- Processos de ação transacionais (F19 a F23)
- Processo de reação não-transacionais (F19 e F20)
- Processos analíticos: (F19, F20 e F22)
- Processo simbólico: coelho branco (F21)

Fonte: Elaborada pelos autores.

Essa sequência compreende o processo inteiro da cirurgia (Tabela 5), repleto de processos narrativos da metafunção representacional. Podemos ver a presença de alguns processos de ação transacionais, que destacam a cirurgia e as mudanças recebidas pela Mrs. Potato Head. Após a cirurgia, há também a presença de um processo de reação não- 
Volume 14 - Número 2 - ago/dez de 2019

transacional (F23), revelando um olhar vazio vindo da personagem, que apenas olha fixamente para frente. Essa reação é resultado do desamparo sentido por ela depois do processo cirúrgico.

Também é possível observar os aspectos conceituais da função representacional. Nos F19, F20 e F22, há ênfase em algumas partes do corpo da participante (rosto e seios), caracterizando processos analíticos. Além disso, também entendemos que a presença do coelho pode ser entendida como um processo simbólico. De acordo com uma das definições do dicionário de símbolos de Herder Lexikon (1998), o coelho é um "símbolo da renovação constante da vida" (p. 60-61), o que pode condizer com o momento tratado no vídeo. O álbum no qual a música está presente possui uma estética voltada para temas da infância, que também pode ser compreendido como outra possibilidade de interpretação desse elemento simbólico, como uma possível referência, talvez, ao livro Alice no País das Maravilhas, de Lewis Carroll.

\begin{tabular}{|} 
Quadro 3: Terceira estrofe da música Mrs. Potato Head \\
Kids forever, kids forever \\
Baby soft skin turns into leather \\
Don't be dramatic, it's only some plastic \\
No one will love you if you're unattractive \\
\hline
\end{tabular}

Fonte: Elaborado pelos autores.

Em relação à narrativa da cirurgia na sequência 5, a terceira estrofe (Quadro 3) se inicia com a forte presença do participante kids (crianças), aplicado na frase completa "crianças para sempre", denunciando a necessidade das pessoas de se manterem jovens e de meios não naturais para tal - no caso presente, a plástica. Na segunda linha, as palavras baby (bebê) e soft (macio), quando unidas, recebem característica adjetival e estão diretamente ligadas a skin (pele), referindo-se a peles macias como as de bebês, que, além disso, são naturais, sem quaisquer interferências externas. Em seguida, o processo to turn (into) (transformar em) e o termo leather (couro) conferem a ideia de que essas peles, uma vez naturais, mudam ao longo da vida, com o envelhecimento. Comparadas aqui com o couro - que mesmo sendo um bom material, é cheio de rugas e marcas -, é possível perceber a necessidade de algumas pessoas de passar por processos artificiais para se manterem jovens.

Em seguida, o uso de (not) to be (não ser) com o atributo dramatic (dramática) evidencia a posição da mulher em situações similares: elas não possuem voz para opinar, devem aceitar as imposições sem objeções, e, caso se oponham, serão taxadas de dramáticas. As exigências da figura masculina são vistas como triviais, porque, afinal, é apenas uma cirurgia plástica. Por fim, a fim de fortalecer mais ainda a ideia da manipulação da figura feminina, há a presença de to love (amar) em conexão com unattractive (pouco atraente), mostrando que um é diretamente relacionado ao outro: nesse momento, no vídeo, Mrs. Potato Head se olha no espelho sem roupas, o que nos dá a entender que ela está insatisfeita com a sua aparência física e acatará a sugestão do parceiro para melhorá-la; caso contrário, é possível que ela não seja mais amada.

Tabela 6: Sequência 6 do videoclipe da música Mrs. Potato Head.

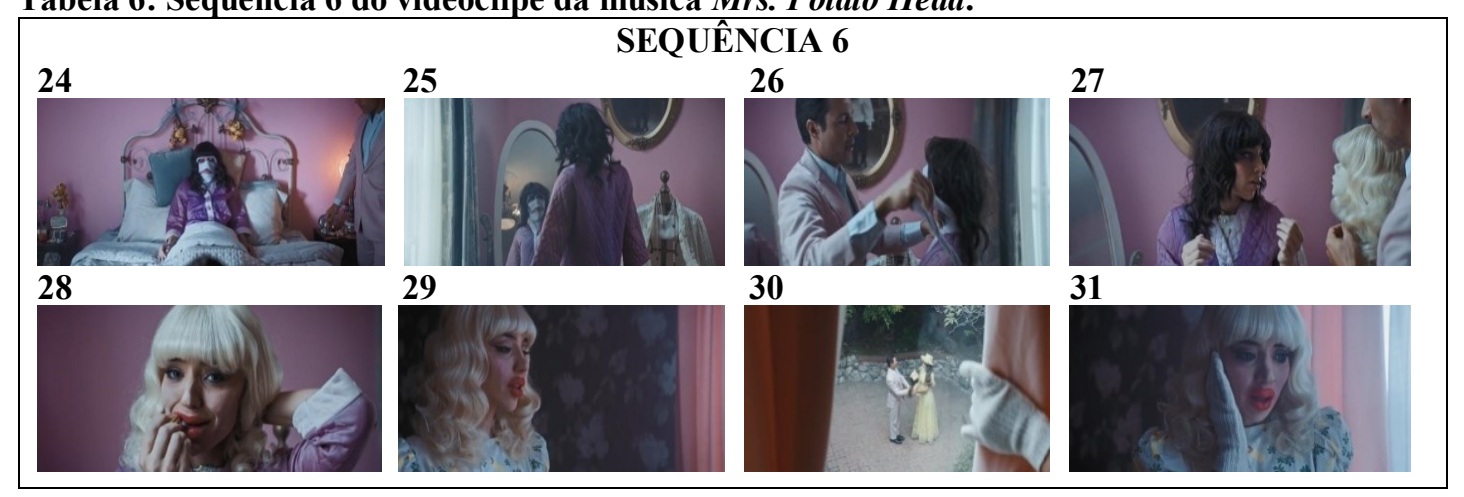


Volume 14 - Número 2 - ago/dez de 2019

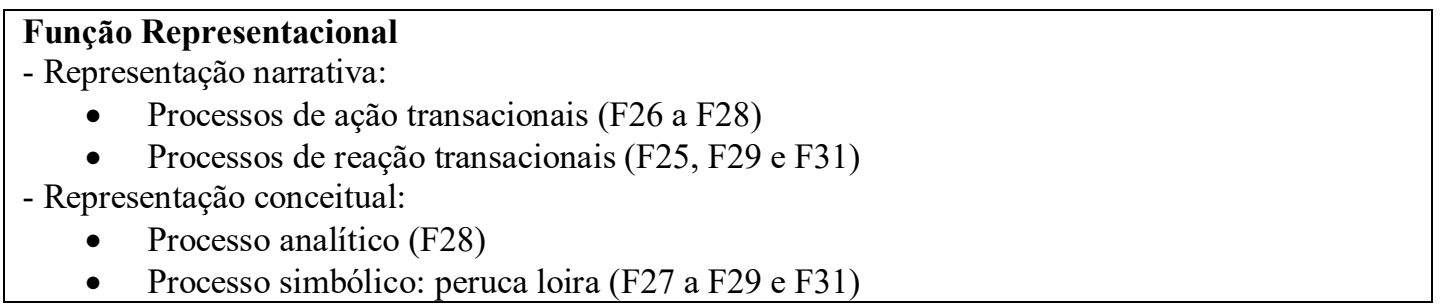

Fonte: Elaborada pelos autores.

A sequência 6 trata do pós-operatório da personagem (Tabela 6), já de volta à sua casa. Podemos notar, nos F26 e F27, processos de ação com dois participantes, mostrando o poder da figura masculina no cenário, deixando a mulher passiva no tocante ao seu próprio corpo. Já os processos de reação demonstram a vulnerabilidade da personagem em toda a sequência, trazendo o foco para seu olhar. Destacamos o F30, no qual o processo de reação se dá em primeira pessoa, colocando-nos no lugar da personagem. Ainda na metafunção representacional, iniciando-se no F27, há a introdução da peruca loira, que aparece no vídeo pela terceira vez. Nesse momento, a peruca funciona novamente como um processo simbólico, dessa vez referido à opressão do homem, que insiste em trazer ainda mais mudanças para a aparência física da mulher.

Os F29 a F31 mostram uma situação de vulnerabilidade e explicita um dos momentos mais pessoais da personagem, de grande intimidade, no qual acompanhamos sua decepção com seu parceiro, visto que, depois de todo procedimento estéticos e de todas as alterações pelas quais passou para agradá-lo, ele surge interessado em outra mulher, que muito se parece à imagem anterior de Mrs. Potato Head, inclusive com cabelo escuro, deixando-a em situação de grande insegurança e fragilidade.

\begin{tabular}{|c|}
\hline Quadro 4: Refrão da música Mrs. Potato Head \\
\hline Oh, Mrs. Potato Head tell me \\
Is it true that pain is beauty? \\
Does a new face come with a warranty? \\
Will a pretty face make it better? \\
Oh, Mr. Potato Head tell me \\
How did you afford her surgery? \\
Do you swear you'll stay forever? \\
Even if her face don't stay together \\
\hline
\end{tabular}

Fonte: Elaborado pelos autores.

Coexistindo com a sequência presente, o refrão traz diversas indagações (Quadro 4). A cantora busca respostas para as dúvidas erguidas por meio das suposições criadas pelo meio social, como visto pelo uso de to tell (contar). As primeiras perguntas são feitas para a personagem feminina da história; de início, há a presença das seguintes palavras em sequência: true (verdadeiro), pain (dor) e beauty (beleza), em paralelo com os quadros iniciais da sequência, que mostram a personagem se recuperando da operação. A ligação entre os três é um forte indicativo do poder que a sociedade tem sobre a figura feminina: é proferida como verdade uma relação direta entre dor e beleza.

A segunda pergunta conta com new (novo) dando característica a face (rosto), conectados a warranty (garantia), conotando um aspecto de produto ao corpo feminino. Ademais, o quarto verso traz novamente face (rosto), dessa vez sendo adjetivado por pretty (bonito); assim como no verso anterior, a conexão dos dois itens com to make (fazer) e better (melhor) caracteriza essa cultura da busca por beleza: se você for mais bonita, sua vida será melhor e você será mais feliz. Isso causa grande pressão em cima de todas as mulheres, principalmente tendo em mente que a beleza buscada é totalmente padronizada por meios midiáticos. 
Volume 14 - Número 2 - ago/dez de 2019

Em seguida, há o início das perguntas para a figura masculina da história. Na primeira, há a ação to afford (pagar) junto de surgery (cirurgia), referenciando o poder aquisitivo do homem, que frequentemente se destaca com relação ao da mulher, criando a possibilidade de imposição de comportamentos que, muitas vezes, não são desejados por elas. Depois, o questionamento do comprometimento do homem em relação à mulher: to swear (prometer), to stay (ficar, na frase seguinte estando na negativa) e, novamente, face (rosto) trazem hesitação e ilustram a falta de balanceamento nesses relacionamentos, nos quais a mulher se esforça muito para agradar o parceiro, enquanto ele pode simplesmente abandoná-la quando assim quiser, como mostrado no videoclipe no F30.

Tabela 7: Sequência 3 (continuação) do videoclipe da música Mrs. Potato Head.

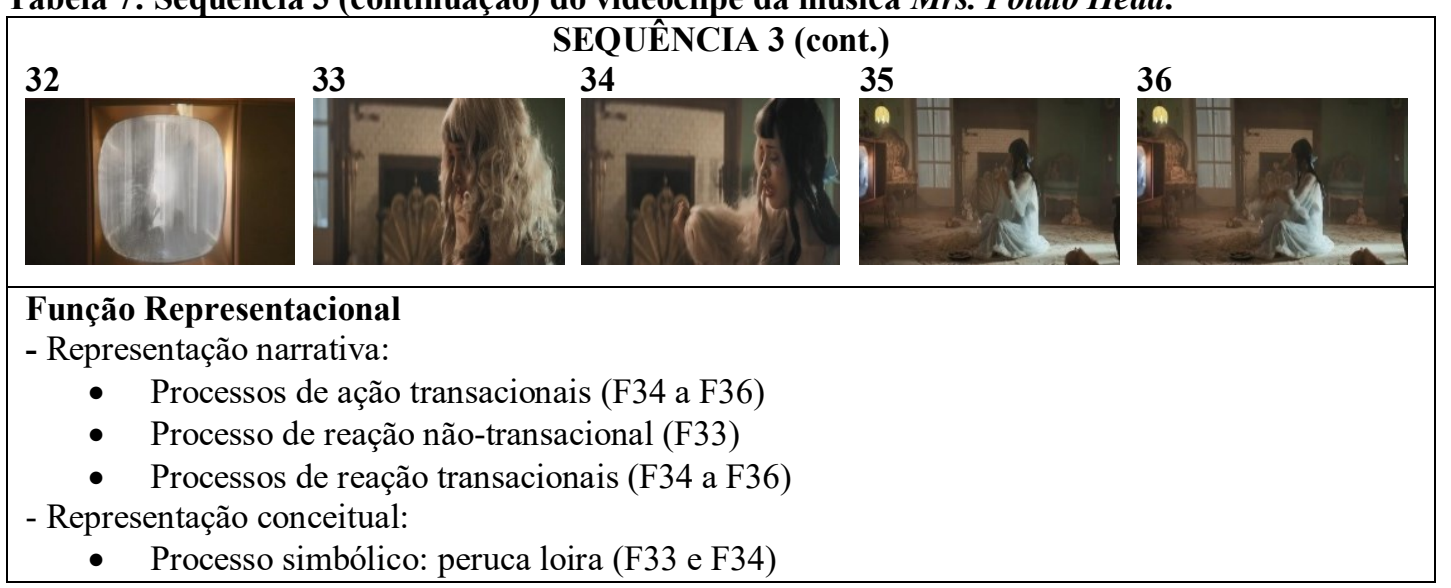

Fonte: Elaborada pelos autores.

Após a história vista na televisão, a sequência 3 é retomada (Tabela 7), com a Cry Baby sentada em frente ao aparelho. Os F33 a F36 constroem processos de reação, com a personagem olhando desconcertada para a TV e para a peruca, uma vez que os eventos narrados na história da Mrs. Potato Head tiveram efeitos evidentes sobre ela. Ela, nesse momento, percebe que não vale a pena tentar seguir moldes ou se deixar levar pela pressão. A personagem, então, retira os acessórios que usava e volta a sua aparência física anterior, como visto nos F34 a F36 por meio dos processos de ação. Em relação à metafunção representacional, há novamente a peruca loira como processo simbólico: ao tirá-la, aparentemente a personagem se nega a seguir normas impostas pela sociedade, livrando-se da pressão sofrida no início do vídeo.

Em relação à letra da música, as próximas duas estrofes não possuem, necessariamente, relação direta com partes específicas do vídeo. Como a pesquisa trata de uma música e sua estrutura particular (versos e estrofes que se repetem, por exemplo), é relevante notar a importância do contexto geral nesses momentos.

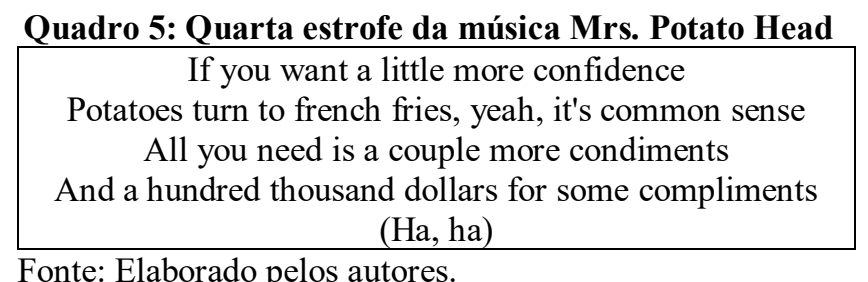

$\mathrm{Na}$ quarta estrofe (Quadro 5), com o intuito de exemplificar a possível vulnerabilidade feminina relacionada às exigências sociais, é insinuada, nos dois primeiro versos, a falta de confiança (confidence), que, a princípio, pode ter solução se você tiver dinheiro. Ademais, potatoes (batatas), french fries (batatas fritas) e condiments (condimentos) criam outra analogia com elementos do dia-a-dia. Nesse caso, coisas aparentemente sem graça (batatas) se tornam 
Volume 14 - Número 2 - ago/dez de 2019

interessantes (batatas fritas) após um processo culinário, com a adição de condimentos. $\mathrm{O}$ momento do vídeo em que ouvimos essa parte da música é exatamente durante a cirurgia da Mrs. Potato Head, esclarecendo a correlação.

Além disso, há a presença de dollars (dólares) e compliments (elogios) nessa estrofe, mostrando, também, o poder do dinheiro e, consequentemente, do homem naquele momento histórico. Essa estrofe também possui relação direta com a sequência 5, que mostra a cirurgia sendo feita. Nela, é possível ver o (teórico) poder do dinheiro de trazer elogios e toda a transformação citada nos versos.

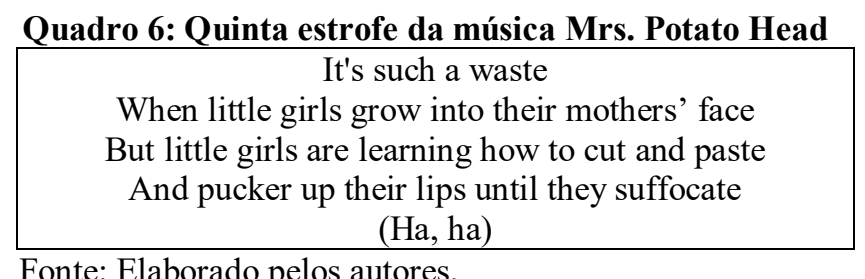

Por fim, a quinta estrofe (Quadro 6) mostra a interferência de dois agentes que são foco da pesquisa. De início, waste (desperdício), little (pequeno), girls (meninas), to grow into (se transformar em), e, mais uma vez, mother's face (rosto), criticam, em conjunto, a influência das normas sociais que fazem as mulheres, desde pequenas, terem interesse em um tipo de aparência específico, geralmente adulto. O segundo agente, a mídia, é referenciado na terceira linha, com a adição das ações to learn (how) (aprender como), to cut (cortar) e to paste (colar), fazendo referência ao comando utilizado na informática (com os botões $c t r l+c$ e $c t r l+v$ ), e, por conseguinte, à intervenção da tecnologia na vida dos jovens hoje em dia e a fácil disseminação de ideias. O resultado disso pode ser observado com a presença de to pucker up (expressão que diz respeito ao ato de contrair os lábios como em um beijo) e lips (lábios), correspondente a um desafio $^{7}$ que ocorreu na internet por volta de 2015, no qual meninas sugavam copos para que seus lábios inchassem e ficassem maiores, assim como os da personalidade Kylie Jenner.

Com efeito, o resultado da análise acima é corroborado pela própria Melanie Martinez em uma entrevista para a revista Vogue, na qual a cantora reforça o conceito por trás da música e do seu videoclipe:

Quando eu escrevi essa música, eu estava passando por muitas inseguranças pessoais sobre minha aparência, e isso foi um lembrete de que eu sou bonita do jeito que eu sou, naturalmente, mesmo que eu não sinta isso. Eu queria que essa fosse a mensagem para outras mulheres, também, que estão lutando com a mesma situação. (MARTINEZ, 2016)

Encontramos, assim, na vida da autora, uma motivação e explicação para sua produção multimodal, indicando que o meio no qual Melanie Martinez se encontrava, as emoções que ela sentia e as situações pelas quais estava passando influenciaram a obra que foi desenvolvida. Esses fatores contextuais que estão implicados na música e no videoclipe, incluindo as práticas discursivas e sociais nas quais os textos se inserem, são questões essenciais para uma análise crítica do discurso, tendo como um de seus principais objetivos investigar o discurso com base em seus parâmetros contextuais a fim de revelar aspectos que podem estar ocultos, como explicitado a seguir:

\footnotetext{
${ }^{7}$ MOYER, Justin. Kylie Jenner Lip Challenge: The dangers of 'plumping that pout'. Disponível em: $<$ https:/www.washingtonpost.com/news/morning-mix/wp/2015/04/21/kylie-jenner-challenge-the-dangers-ofplumping-that-pout/?noredirect=on\&utm_term=.a6376833754d $>$ Acesso em: 4 de abril de 2018.
} 
Volume 14 - Número 2 - ago/dez de 2019

Assim sendo, ao analisar textos criticamente [analistas críticos do discurso] não estão interessados apenas nos textos em si, mas em questões sociais que incluem maneiras de representar a "realidade", manifestação de identidades e relações de poder no mundo contemporâneo. (MEURER, 2005, p. 5)

Ao notarmos que o videoclipe procura questionar noções pré-estabelecidas em um discurso hegemônico sobre gênero, por meio de relações de poder em contextos sociais e institucionais, também precisamos discutir o texto como prática discursiva.

Sabemos que o texto é de autoria feminina. Melanie é uma mulher de 22 anos que possuía inseguranças em relação a sua aparência. Assim, entendemos que esse pode ter sido um fator motivador para o processo criativo da canção e do videoclipe, visto que suas marcas como indivíduo perpassam sua identidade, que, por sua vez, é refletida no texto multimodal em questão. Quanto aos processos de distribuição e de consumo, tanto os videoclipes quanto o CD Cry Baby foram divulgados principalmente pela internet, o que, possivelmente, traz visibilidade maior que veículos como o rádio e a televisão na sociedade contemporânea. Apesar disso, o público-alvo da cantora é constituído, principalmente, de adolescentes, influenciados não apenas pelo seu estilo musical, mas pela estética utilizada (vídeos com muitas cores) e temáticas tratadas.

Nas considerações do texto como prática social, interessa-nos discutir como o texto reflete determinadas práticas sociais, enfatizando conceitos de ideologia e de hegemonia, bem como questões sociais relevantes, como é o caso das representações de gênero enfatizadas nesta pesquisa. Como dito anteriormente, a música e o conteúdo mostrados no vídeo de Mrs. Potato Head procuram contestar uma ideia pré-concebida de que mulheres são inferiores às suas contrapartes masculinas, e de que deveriam, assim, se submeter a situações às quais nunca se exporiam naturalmente. Isso é amplamente ilustrado no videoclipe, por exemplo, no momento em que se percebe que a Mrs. Potato Head é substituída por outra mulher, e em que a Cry Baby se arrepende de ter tentado se encaixar no padrão estético sugerido pela propaganda televisiva.

Como afirmam Benwell e Stokoe (2006), "quem somos um para o outro (...) é realizado, disputado, atribuído, resistido, administrado e negociado no discurso" (p. 4), corroborando a noção do seu poder constitutivo em práticas textuais e contextos particulares. Podemos observar, portanto, que essa criação de percepções acerca de questões da vida em sociedade se revela no videoclipe em análise, especialmente pelo fato de que em décadas anteriores o discurso vigente parecia autorizar uma visão de superioridade masculina.

Na presente pesquisa, há uma ilustração da maneira como relações assimétricas de poder podem desestabilizar sujeitos que se encontram em situação de opressão. Ao observarmos o personagem masculino exercer grande influência sobre a autoestima da personagem feminina, forçando-a a submeter-se a procedimento cirúrgico para agradá-lo, evidenciamos o quanto a mulher parece (ainda) estar circunscrita a moldes específicos de aparência física - o que contribui fortemente para uma cultura de propagação de estereótipos sobre feminidade.

A outra forma de influência largamente demonstrada no vídeo é a mídia. Podemos observar, dessa maneira, o processo de criação de representações parciais da realidade através do impacto dos meios midiáticos, e, mais especificamente, as possíveis representações da mulher na sociedade, delineadas pelo comercial de TV e pelo evidente controle que ele possuiu sobre a personagem Cry Baby: foi criado um estereótipo da figura feminina que era divulgado através de comerciais. A personagem, ao perceber que não se encaixava nesse padrão, não viu outra saída a não ser tentar mudar sua aparência, especialmente devido à pressão por agradar seu parceiro.

Percebemos, dessa maneira, que a mídia é um agente de grande protagonismo na construção de uma ideia coletiva sobre questões sociais complexas, dentre as quais destacamos as identidades de gênero. Evidencia-se, assim, a importância do letramento midiático crítico, no sentido de possibilitar que as pessoas compreendam que certas visões sobre assuntos 
Volume 14 - Número 2 - ago/dez de 2019

particulares são construídas em intersecção com questões de poder e ideologia. Afinal, quem domina o acesso aos meios midiáticos? Quem tem mais espaço de fala para construir tais visões sobre a vida em sociedade?

Diante dessa problemática, o videoclipe em análise oferece uma importante crítica à padronização da imagem e à limitação do espaço da mulher em sociedade, que parecem fixar papeis sociais em um imaginário coletivo que não condizem com as conquistas históricas no sentido da consolidação da igualdade de gênero na contemporaneidade.

\section{Considerações finais}

A representação das mulheres, tal como construída pela mídia, exerce impacto na maneira como os atores sociais se relacionam com elas cotidianamente, quer seja em espaços familiares, sociais ou do trabalho. O objetivo geral desta pesquisa foi investigar representações das identidades da mulher no videoclipe Mrs. Potato Head, contribuindo, dessa maneira, para a discussão sobre essa relevante temática.

Pudemos destacar as relações de poder e de hegemonia presentes no vídeo e na letra da música, percebendo a forma como a personagem feminina está representada de maneira fragilizada e submissa às influências da mídia e da figura masculina. Além disso, por meio da análise multimodal, alguns recursos como zoom e proximidade, desfoque do plano de fundo, posicionamento dos participantes e objetos, cores e itens conceituais, tais como simbolismos e classificações por meio do texto verbal, contribuem para a construção de representações particulares sobre a mulher nos termos já descritos.

Também merece destaque a maneira como essas relações de hegemonia e o poder da mídia interferem na percepção social sobre as relações de gênero. Essa premissa se revela ao percebermos, através da história, como toda a situação foi normalizada. Isso se reflete nas atitudes de Mrs. Potato Head que não se opõe a nada que foi mostrado no videoclipe apesar de seu evidente descontentamento. Percebemos, assim, que o poder da mídia e de atores sociais em posições privilegiadas de poder exercem influência sobre o discernimento de outros grupos e/ou atores sociais.

Por fim, o último objetivo específico traz a questão da relevância da leitura crítica da mídia, bem como sua utilidade em relação aos multiletramentos. $O$ fato de a mídia ser um agente constante na vida em sociedade evidencia essa necessidade, dado que a quantidade de informações a que temos acesso é imensa, gerando dificuldade de avaliarmos sua autenticidade e relevância, criando, assim, maiores chances de sermos facilmente manipulados caso não tenhamos a competência leitora crítica para analisarmos o que lemos/vemos.

Nesse sentido, podemos perceber que a influência da mídia e o papel social dominante do homem são elementos essenciais para se compreender como as identidades da mulher são representadas na sociedade atual por meio do videoclipe analisado. De forma a mudar esse cenário, é importante que tratemos dessas questões desde cedo, com a população mais jovem, ainda nas escolas. Assim, o papel do professor se mostra cada vez mais importante. Sabemos que ainda há um longo caminho pela frente, mas a utilização de práticas de multiletramentos e da análise crítica do discurso da mídia podem facilitar esse trajeto e ajudar a criar relações pessoais e sociais mais igualitárias.

\section{Referências}

BENWELL, B.; STOKOE, E. Discourse and identity. Edinburgh: Edinburgh University Press, 2006.

BEZERRA, F. Multimodality in the EFL classroom. BELT-Brazilian English Language Teaching Journal, v. 2, n. 2, p. 167-177, 2012.

COPE, B.; KALANTZIS, M. (Orgs.). A pedagogy of multiliteracies: learning by design. Nova York: Palgrave Macmillan, 2015. 
Volume 14 - Número 2 - ago/dez de 2019

Multiliteracies: literacy learning and the design of social futures. Londres: Routledge, 2000. p. 9-36.

CORACINI, M.; CARMAGNANI, A. (Orgs.). Mídia, exclusão e ensino: dilemas e desafios na contemporaneidade. Campinas: Pontes Editores, 2014.

FAIRCLOUGH, N. Language and power. 3 ed. Londres, Nova York: Longman, 2015[1989].

Critical discourse analysis. Londres, Nova York: Longman, 1995.

HEBERLE, V. Critical reading: Integrating principles of critical discourse analysis and gender studies. Ilha do Desterro, v. 38, 115-138, 2000.

KELLNER, D. Cultural studies, identity and politics between the modern and the postmodern. London: Routledge, 2003.

; SHARE, J. Educação para a leitura crítica da mídia, democracia radical e reconstrução da educação. Educação \& Sociedade. Campinas, v. 29, n. 104, p. 687-715, 2008.

KRESS, G. R.; VAN LEEUWEN, T. Reading images: the grammar of visual design. Routledge, 1996.

LAKOFF, R. Language, gender, and politics: putting "women" and "power" in the same sentence. In: HOLMES, J.; MEYERHOFF, M. (Orgs.). The handbook of language and gender. Nova Jersey: Blackwell Publishing Ltd, 2003. p. 161-178.

LEXICON, H. Dicionário de símbolos. Editora Cultrix, 1998.

MARTINEZ, M. A look inside Melanie Martinez's beautifully twisted world. Vogue. Agosto, 2016. Entrevista concedida a Mathias Rosenzweig. Disponível em: $<$ https://www.vogue.com/article/melanie-martinez-cry-baby-lollapalooza $>$. Acesso em: $7 \mathrm{de}$ fevereiro de 2018.

Mrs. Potato Head. Youtube. Dezembro, 2016. Disponível em: $\overline{<\mathrm{https}}$ //www.youtube.com/watch?v=wkri1NUq9ro $>$ Acesso em: 8 de agosto de 2017.

MEURER, J. Gêneros textuais na análise crítica de Fairclough. In: ; BONINI, A.; MOTTA-ROTH, D. (Orgs.). Gêneros, teorias, métodos, debates. São Paulo: Parábola Editorial, 2005. p. 81-106.

MOYER, J. Kylie Jenner lip challenge: The dangers of 'plumping that pout'. The Washington Post. Abril, 2015. Disponível em: <https://www.washingtonpost.com/news/morning$\mathrm{mix} / \mathrm{wp} / 2015 / 04 / 21 /$ kylie-jenner-challenge-the-dangers-of-plumping-that-

pout/?noredirect $=$ on\&utm_term=.a6376833754d $>$ Acesso em: 4 de abril de 2018.

NASCIMENTO, R.; BEZERRA, F.; HEBERLE, V. Multiletramentos: iniciação à análise de imagens. Linguagem \& Ensino, Pelotas, v. 14, n. 2, 529-552, 2011.

VAN LEEUWEN, T. Moving English: the visual language of film. In: GOODMAN, S.; GRADDOL, D. (Orgs.). Redesigning English: new texts, new identities. Londres: Routledge, 1996. p. 81-103.

WODAK, R. Do que trata a ACD - um resumo de sua história, conceitos importantes e seus desenvolvimentos. Linguagem em (Dis)curso, Tubarão, v. 4, n. especial, 223-243, 2004. 